\title{
The Challenge of Individual Rights Mental Health Review Tribunals
}

\section{SIR JOHN WOOD}

The concept of 'individual rights' loudly, and often extravagantly, proclaimed has become a predominant feature of our legal system, marking a distinct change of approach over the last $\mathbf{3 0}$ or $\mathbf{4 0}$ years. The law is not now looked at merely as a way to regulate relationships or to redress wrongs - it is primarily seen as creating a structure of rights. It is an approach that has been developed aggressively in the USA where there has long been great emphasis on the individual. Rights tend to be expressed as generalisations - to life, to free speech, to freedom - which inevitably leads to a false and exaggerated impression, as consideration of the nature and extent of any of the particular rights will show.

\section{The system of rights}

The jurisprudence of the British legal system, where unwritten common law principles play an important role, has traditionally been somewhat sceptical of grand 'Declarations of Rights'. There has been concentration on the question whether an individual, suffering what is believed to be an injustice, was entitled to a remedy. A specific rule indicating a remedy - whether of statute or case law - was valued more than a general expression of a right.

There are several reasons why this approach is theoretically sounder. Every right can be alternatively expressed as someone else's duty and the tendency of a rights-based formulation is to underestimate the resistance that may exist to a claim of right. Indeed, it is also obvious that there are conflicting rights the right to free speech is undoubtedly fettered by countervailing rights such as that not to be defamed. In addition rights have to be properly exercised and the way they are used may give rise to a counterclaim of, for example, negligence.

Rights are in fact set by three principal regulators. The most obvious is legislation, which consistently creates rights. It equally imposes duties, as the mental health legislation - the Statutes and Statutory Rules illustrate. They give great powers - detection is the obvious example - but equally the law provides sanctions against those who misuse those powers. The most usual legal device for regulating rights voluntarily is contract. This is so obvious that little need be said about it. In theory, contract is a voluntary agreement and classically is regarded as two parties reaching and agreeing a mutually acceptable position. Again practice diverges, since the relative power of the contracting parties may be unbalanced. It is for this reason that large sections of statute and case law are aimed at protecting weaker individuals such as the consumer. The third force, of growing importance, is the concept, already mentioned, of the tort of negligence. This important aspect of the law encompasses the basic concept that each person owes a duty of care to his neighbour, defined basically as anyone he should reasonably be aware may be injured by his action. It is noteworthy that the definition here uses not the concept of right but that of duty. Under the wide umbrella of these principles the courts have been able to review conduct and award appropriate damages where the duty has not been fulfilled.

\section{Setting the standards}

It is important to recognise where the law seeks the standards it will apply. This will be apparent from what has just been said. A judge will look first at any relevant statutory law. This may be accompanied by relevant case law, which will both clarify the meaning of the statute and of fer examples of the application of the law (often numerous). It will then be necessary to consider any agreements relevant to the relationship between the parties. There may be provisions which set out how the parties intended their relationship to be conducted and judged, which will apply unless there is some overriding objection such as illegality. Finally, the law increasingly lays general duties on everyone, particularly when they are doing things which require skill and care which are likely to affect others. Almost any activity walking, driving, playing sport - has given rise to a large number of successful actions for negligence. The more skilled the occupation-and medicine and psychiatry in particular rank highly in this - the greater the standard of care the law demands.

It is appropriate to note here that the professions themselves are able to influence, quite markedly, the standards that the court will apply. There are many aspects to this. A great deal will fall under the concept of good orthodox practice, but where complicated 
disputes arise the profession itself will be called on, through the device of 'expert' witnesses, to clarify for the judge the standards he should use as his yardstick. Like so much in legal practice, there is a degree of artificiality about this process. Many readers will have experience of the process and will be aware that lawyers are able to profit from the tendency of qualified experts to disagree and to include mavericks within their ranks. Lawyers find such disagreements particularly useful for the purposes of litigation.

\section{The challenges}

There are three aspects of the system of dealing with mentally ill patients, especially where detention under an Order is involved, that present challenges to everyday practice and so merit further consideration. They are:

(a) the requirements of the statutory legal system created to protect psychiatric patients

(b) the clarity and stability of the professionally accepted standards of good practice

(c) the availability of resources to ensure that what is called for by those standards is made available to the patient.

It is essential to the well-being of all the professions concerned with the care of the mentally disabled that the law seeks to impose only standards that are both reasonable and practicable.

\section{Mental health law and practice}

Not surprisingly the care, and particularly the detention, of mental patients has given rise to a special body of law, created in its modern form in 1959 and now largely to be found in the Mental Health Act 1983. This enables a patient to be lawfully detained and provides for the periodic right to challenge such detention. It is important that legislation of this nature should be both available and effective.

For this reason it is inevitable that the structure and details of the system should be reviewed from time to time. It is nearing the time when a review and debate on how the system is working at present will be useful. The structure of the system is satisfactory, laying down clear rules for detention and giving periodic rights to appeal to a detained patient. However, it is not difficult to identify aspects which would benefit from review. For example, the short-term order under Section 2 of the 1983 Act has to be speedily available, usually being heard about the end of the second week of detention. This is essential for those newly diagnosed, but the longterm schizophrenic who breaks down is often put on a Section 2 Order. By the time of the hearing the patient will have been reintroduced to a proper dosage of drugs and showing marked signs of improvement. But most often insight is not yet strong enough to warrant discharge of the Order, as it may well be in another week or so. It is features such as this that require reconsideration. For example, it might be possible to envisage a longer Section 2 Order for those who have had previous breakdowns, with the appeal to be heard in the fourth or fifth week of detention. By that time it is likely many patients will be well enough to have the Order removed by the responsible medical officer (RMO) without necessity for a tribunal. The aim should be to allow the challenge at the time when protection is needed early for the first admission, later perhaps for others.

Such difficulties rarely arise in Section 3 cases, where the hearing of the challenge is likely to be somewhat tardy through pressure on the tribunals. In these cases the issue is likely to involve more than the question of diagnosis. The patient's need for care and protection to ensure safety has complicated medical and social problems and these raise the question as to the exact role of the tribunal. Strictly interpreted, it is merely to rule on the need for the Order, for it has no power to rule on either treatment or level of control. Yet in many such tribunal hearings the most useful aspect is a constructive discussion of the case between the experts in the various disciplines present. It may, therefore, be appropriate to consider how this constructive aspect of cases could be given a place in the legislation, without detracting from the overall authority of the RMO.

Perhaps the most important and difficult cases are those involving patients whose detention arises from court proceedings. They range from individuals who are responsible for very serious crimes indeed to inadequate persons who are unable to avoid trouble. They are able to have frequent reviews by a tribunal when any form of relaxation of detention is unlikely for many years - which is itself potentially unsettling. Again, some fresh thinking on this seems appropriate, since a tribunal hearing (or a series of hearings) unlikely to lead to release if narrowly confined to the question of detention, is without real purpose. Before the tribunals had power to discharge in restricted cases, they had the duty to report to the Home Secretary, with whom responsibility lay. So each hearing was used to build up a series of reports which the Home Secretary would use to help reach a decision. There may well be merit in asking the tribunals to revive this process of building up 
assessments and recommending consideration of change. It would give each tribunal a constructive role as a key part of its terms of reference.

The availability of the conditional discharge goes some way to meeting this point, and it might be counterproductive to use the analogy of a case conference, but where the patient's liberty has been forfeit there is much to be said for a formal review of progress - though conducted humanely - that is specifically able to focus on a wider range of aspects of the case than merely release into the community.

\section{Psychiatric practice}

Although the practice of psychiatry has made rapid strides over the past few decades, there is no doubt that one of the difficulties of structuring a constructive system of legal challenge to detention is the continuing uncertainty and debate on many aspects of psychiatric care and control. It is a weakness that is compounded, to differing degrees at different times and in different hospitals, by the possibility of divergence between the psychiatric and the socialwork view of a patient's needs.

This is not the place to set out the very many ways in which these tensions can arise. The reasons are easy to identify. There are very many 'fashions' in looking at the psychiatric illnesses and treating them. The role of the psychologist is a good example. For a time all patients in the major hospitals were thoroughly tested and assessed. It is now more common for this to be regarded, at best, as unnecessary or even as contrary to the aim of treating 'the whole' person. It is not necessary to take sides on a debate such as this to point out that there is need for care to avoid major swings of opinion that appear to an outsider as hard to justify intellectually.

Such swings can be seen in many more guises. The use of restraint, either in the sense of keeping the patient within the hospital or in controlling behaviour in the hospital to generally accepted social standards, is another area on which practice varies greatly from hospital to hospital and from consultant team to consultant team. For a local hospital to be unable to 'find' within the hospital three patients whose detention was on one particular day to be reviewed by a tribunal is merely an extreme example of the uncertainties that can creep into practice.

It would be wrong to expect the diagnosis of illness and its care and control to be as uniform in psychiatry as in most other branches of medicine. But it is important, especially as external safeguards are imposed by law, that the College, and psychiatrists themselves, adhere to an agreed range of practices. It is in this context that 'rights of the individual' needs particular attention. A patient who is mentally ill is not deprived of all rights, but it has to be accepted that the full panoply of rights enjoyed by a fit person have to be tempered to the patient's disability. While the disability lasts, it is the duty of the consultant and of other carers, particularly social workers, to substitute sound judgement to guide, and if necessary control, the patient's conduct. It is one of the indirect consequences of review by a tribunal that such a balance will be reviewed and the necessary level of care and control endorsed. In such circumstances to concentrate solely on 'loss of rights' is but half of the responsibilities.

\section{Resources}

There is no doubt that the availability of appropriate resources is one of the most important factors in the balance between freedom and control. It is necessary to stress that equally as important as availability is ease of transfer, without undue difficulty or delay, from one level of care and control to another. This applies to moves in both directions - to less controlled care when there is improvement and to greater care when there is a relapse. Experience shows this to be an increasing difficulty, surprisingly in both directions.

It may well be that much of this is due to lack of resources but lack of clarity as to responsibility could be another major hazard. The most frustrating aspect of the work of the tribunals arises here. Most serious is the realisation that the question of classification of illness and identification of need gets involved in the problem of the availability of resources and the control of the resources. The logical placement of, say, psychopaths or chronic schizophrenic patients in places with the appropriate level of care is apparently beyond efficient organisation. The reasons are, it has to be said, complex, but rarely, on examination, justifiable.

It is pleasing that there are an increasing number of relatively new units offering levels of care that indicate what can be done. Yet there are many patients whose history between breakdowns indicate that there are serious delays in transfers and gaps in care. Sadly, it appears that the undoubted financial pressures may not only affect good care but also be used to distort the rational classification of patients. The closing of the large mental hospitals of former times has not been met by clear alternatives readily available for those who need them. There are some excellent developments, but the uncertainties of both the psychiatric and social work professions have been used in part to justify failure to provide adequate resources. 


\section{Conclusions}

The tasks undertaken by psychiatry and the other professions treating and caring for the mentally ill are difficult in the extreme. The work attracts a great deal of publicity and is closely monitored by groups representing patients. Society has additionally decreed that the law itself should be used to provide a form of overall supervision and the principal instrument of this is the system of Mental Health Review Tribunals.

There is an unfortunate underlying concept in the minds of many of the lawyers and psychiatrists concerned that they are there to 'check on errors' and protect rights. Experience shows that major misjudgments are very rare. A system aimed only at those essential aspects is bound to be sterile, much of its work being 'going through the motions' in cases where there is little cause for concern. Such a limitation would be a waste, and happily in practice the tribunals have tended to adopt a more constructive role, usually with the encouragement of all concerned.

As well as providing a safeguard for the patient against wrongful detention, that constructive role involves helping to identify those who need psychiatric help as well as social support, enabling those who resist help to be treated as humanely as possible, and checking that such treatment and care is not concealing over-zealous control. Although not fully spelt out, since the enactment of the Mental Health Acts of 1959 and 1983 a dialogue between the patient and the patient's representative and the doctors and social workers concerned has been encouraged at tribunal hearings. It is rarely resented, and most patients expect that level of interest to be taken in their problems. As the mental health legislation ages and reform is considered, and as the provision of resources adequate for need becomes more and more difficult, it is important that the constructive aspects of the work of the Mental Health Tribunals are recognised. A patient's rights, however that concept is interpreted, are best protected by periodic constructive review, so that needs can be identified and pressure exerted to meet them.

This editorial is a short version of a lecture delivered by Sir John Wood to the 1994 Annual Meeting of the Royal College of Psychiatrists, in Cork.

Sir John Wood, 44 Ranmoor Cliffe Road, Sheffield S10 3HB

(First received 10 August 1994, final revision 14 September 1994, accepted 19 September 1994) 